\title{
Long-term disease-free survival in advanced melanomas treated with nitrosoureas: mechanisms and new perspectives Xavier Durando*1, Emilie Thivat ${ }^{1}$, Michel D'Incan ${ }^{2}$, Anne Sinsard ${ }^{1}$, Jean- Claude Madelmont ${ }^{3}$ and Philippe Chollet $^{1}$
}

\author{
Address: ${ }^{1}$ Medical Oncology Unit, Centre Jean Perrin, Clermont-Ferrand, France, ${ }^{2}$ Dermatology Department, Hôtel-Dieu, Clermont-Ferrand, \\ France and ${ }^{3}$ INSERM U484, Clermont-Ferrand, France \\ Email: Xavier Durando* - xavier.durando@cjp.fr; Emilie Thivat - recherche.clinique@cjp.fr; Michel D'Incan - mdincan@chu-clermontferrand.fr; \\ Anne Sinsard - recherche.clinique@cjp.fr; Jean-Claude Madelmont - madelmont@inserm484.uccclermont1.fr; \\ Philippe Chollet - philippe.chollet@cjp.fr \\ * Corresponding author
}

Published: 15 November 2005

BMC Cancer 2005, 5:147 doi:10.1/86/147|-2407-5-147
Received: 17 December 2004

Accepted: 15 November 2005

This article is available from: http://www.biomedcentral.com/I47I-2407/5//47

(C) 2005 Durando et al; licensee BioMed Central Ltd.

This is an Open Access article distributed under the terms of the Creative Commons Attribution License (http://creativecommons.org/licenses/by/2.0), which permits unrestricted use, distribution, and reproduction in any medium, provided the original work is properly cited.

\begin{abstract}
Background: Median survival of metastatic malignant melanoma is 6.0 to 7.5 months, with a 5 year survival of $\sim 6.0 \%$. Although long-term complete remissions are rare, few reports describe cases after chemotherapy. Fifty-three patients with metastatic melanoma were treated with Cystemustine, a chloroethyl nitrosourea (CENU) $\left(60\right.$ or $\left.90 \mathrm{mg} / \mathrm{m}^{2}\right)$.

Case presentation: We describe 5 cases, presenting with complete response with long-term disease-free survival of long-term remission of 14, 12, 9, 7 and 6 years after Cystemustine therapy alone.

Conclusion: Long-term survival has already been described in literature, but in all cases they have been obtained after chemotherapy associated with or followed by surgery. But despite these noteworthy and encouraging but also rare results, it appears essential to increase cystemustine efficiency.
\end{abstract}

\section{Background}

Melanoma has become an important public health issue because of its rising incidence in the Caucasian population. Even though, most cases are cured by surgery alone in the early stages of the disease, advanced melanoma has a poor prognosis. Therapeutic strategies of metastatic malignant melanoma are based on multiple treatment including chemotherapy (dacarbazine, platinum analogs, chloronitrosoureas (CENU), vinca alkaloïds or taxanes) and immunotherapy (interferon $\alpha$, interleukine 2), both as single agents or in association.
Median survival of metastatic malignant melanoma is 6.0 to 7.5 months, with a 5 -year survival of approximately $6 \%$ [1]. Although long-term complete remissions are rare, some authors have reported cases after chemotherapy treatment [2-6].

Cystemustine $\left\{N^{\prime}-\right.$ (2-chloroethyl)- $N$ - [2-(methyl sulphonyl)ethyl]-N'-nitrosourea\} is a CENU derived from 2chloro-ethylnitroso-carbamoylcysteamine (CCNC); it is synthesised in INSERM U484, Clermont-Ferrand [7]. This new compound has demonstrated an equivalent and often better chemotherapeutic index for solid tumours than other chloroethylating agents currently in use [8]. 
Table I: Patient characteristics.

\begin{tabular}{|c|c|c|c|c|c|}
\hline Patient & I & 2 & 3 & 4 & 5 \\
\hline $\begin{array}{l}\text { Patient age/disease } \\
\text { discovery (year) }\end{array}$ & 55 & 33 & 63 & 44 & 43 \\
\hline Primary disease date & April 1981 & August 1985 & January 1984 & January 1997 & August 1993 \\
\hline Primary disease location & Right ankle & Left calf & Left ankle & Left arm & Left thorax \\
\hline Clarck index & III & $\mathrm{V}$ & IV & III & III \\
\hline First recurrence date & March 1988 & June 1986 & April 1987 & January 1997 & March 1998 \\
\hline $\begin{array}{l}\text { Previous treatment for } \\
\text { advanced } \\
\text { disease (before } \\
\text { cystemustine) }\end{array}$ & None & $\begin{array}{c}\text { Dacarbazine Vindesine } \\
\text { (6 cycles) } \\
\text { Dacarbazine Vinblastine } \\
\text { (6 cycles) } \\
\text { Dacarbazine Interferon } \alpha 2 a \\
\text { (6 cycles) }\end{array}$ & $\begin{array}{l}\text { Interferon } \alpha 2 \mathrm{a} \\
\text { Radiotherapy }\end{array}$ & None & $\begin{array}{l}\text { Dacarbazine } \\
\text { (8 cycles) }\end{array}$ \\
\hline Treatment start date & March 1988 & May 1990 & August 1990 & February 1997 & Novembre 1998 \\
\hline Custemustine dose $\left(\mathrm{mg} / \mathrm{m}^{2}\right)$ & 90 & 60 & 90 & 90 & 60 \\
\hline Metastatic sites & $\begin{array}{l}\text { Popliteal mass } \\
\text { Lymph node }\end{array}$ & Lung Bone & Lymph node & $\begin{array}{l}\text { Lymph node Sub- } \\
\text { cutaneous }\end{array}$ & Lung \\
\hline $\begin{array}{l}\text { Treatment concomitant to } \\
\text { Cystemustine }\end{array}$ & $\begin{array}{l}\text { Surgery (March } \\
\text { I988) }\end{array}$ & None & None & None & None \\
\hline Recurrence of the disease & None & None & None & None & None \\
\hline Date of death & November 2000 & Alive & March 2000 & Alive & Alive \\
\hline Disease free survival (years) & 12 & 14 & 10 & 7 & 6 \\
\hline
\end{tabular}

We describe 5 cases treated with Cystemustine (60 or 90 $\mathrm{mg} / \mathrm{m}^{2}$ ) for metastatic melanoma showing complete responses with long-term survival (survival time 24 months or longer).

\section{Case Presentation}

A series of 53 patients has been treated with Cystemustine administered as a $15 \mathrm{~min}$ iv infusion every 2 weeks. 30 patients were included in a phase II national and multicentric study, whereas other 23 patients received a Cystemustine compassionate treatment.

In the phase II study, patients provided written informed consent after they were informed about the objectives of the study. The protocol designs and relative modifications were fully approved by the ethic committee. The patients received Cystemustine 60 or $90 \mathrm{mg} / \mathrm{m}^{2}$. The median number of Cystemustine cycles was 3 (range, 2 to 7 cycles). 28 out of 30 patients were assessed for disease response ( 2 patients were included without measurable disease according to World Health Organisation (WHO) criteria. The overall response rate was $17.9 \%$, with 3 complete responses and 2 partial responses. Two patients showing complete response had been treated with Cystemustine $90 \mathrm{mg} / \mathrm{m}^{2}$, the third patient received Cystemustine $60 \mathrm{mg} / \mathrm{m}^{2}$.

Patients given "compassionate treatment" received 60 $\mathrm{mg} / \mathrm{m}^{2}$ of Cystemustine. The median number of Cystemustine cycles was 3 (range, 1 to 27 cycles). Among these 23 patients, 15 were assessed for disease response (i.e. patients with measurable disease according to WHO criteria). Four complete and two partial responses were observed. All patients were treated with Cystemustine 60 $\mathrm{mg} / \mathrm{m}^{2}$.

Among these 53 patients, 5 complete responses with longterm survival occurred. In 4 cases, complete responses were obtained after Cystemustine treatment alone, whereas, for the fifth patient, one of the metastatic lesions was excised at the early beginning of the treatment. The characteristics of these 5 patients are summarised in the "patient characteristics" table 1.

Patient 1 was a 55 year woman presented with a level III Clark right ankle malignant melanoma excised on April 1981. In 1988, she displayed an inoperable popliteal mass associated with a large right inguinal adenopathy. Between March and August 1988, she received 13 cycles of Cystemustine $90 \mathrm{mg} / \mathrm{m}^{2}$. CR was documented by clinical and echographic exams in August 1988. The main toxicities of treatment were nausea, vomiting and thrombopenia. These last ones have led to dose reduction and treatment delay. This patient died of stroke on November 2000 without any recurrence of the disease.

Patient 2 was a 33 year woman presented with a level IV Clark left calf malignant melanoma excised on August 1985. Between 1986 and 1990, several relapse of melanoma were diagnosed. The patient has been successively treated with vindesine/dacarbazine, vindesine/ dacarbazine, and dacarbazine/interferon $\alpha$. Hormono- 
therapy with tamoxifene was then introduced with close clinical follow-up. In 1990, she presented with right tibiae metastasis and two pulmonary lesions. Treatment with Cystemustine $60 \mathrm{mg} / \mathrm{m}^{2}$ was introduced for 18 cycles. After 6 cycles, complete regression of pulmonary lesions was observed, but bone lesions were always present in spite of a significant improvement. Tumour assessment after 17 cycles revealed CR to treatment. The main toxicity was haematological, with neutropenia and thrombopenia, that necessitated course delay and dose reduction.

Patient 3 was a 63 year woman presenting with Clark level IV malignant melanoma on left ankle, excised in January 1984. Three years later, tumour recurrence was diagnosed on the left calf. An adjuvant treatment with interferon was introduced (but interrupted after the first infusion because of an allergic reaction), followed by $3 \times 18$ Gy cycles of radiotherapy in June 1987. In August 1988, a node was detected at the lower part of the left popliteal pit, and was excised in December 1988. In September 1990, supra-clavicular and lombo-aortic nodes were detected. The patient received 11 cycles of Cystemustine $90 \mathrm{mg} / \mathrm{m}^{2}$, and a CR was obtained after 8 cycles. Haematological toxicities occurred with severe thrombopenia, leading to course delays and platelet transfusion after the $8^{\text {th }}$ infusion. Except for the haematological toxicity, treatment was well tolerated. However, a systematic exploration of respiratory function in January 2000 showed a severe hypoxia and confirmed the diminution of carbon monoxide capacity found 5 years earlier.

In July 1998, myelodisplasic syndrome was diagnosed. She died in March 2000 during severe aplasia, nevertheless her meanoma was still in complete remission for 9 years and month.

Patient 4 was a 44 year male presenting Clark level III malignant melanoma located on left arm. Tumour excision was performed on January 1997 and completed with a node dissection. One node of 11 removed was metastatic. Imaging assessment found also a superficial $2 \mathrm{~cm}$ left axillary node as well as $2-3$ infracentimetric metastatic subcutaneous nodes in the chest wall. The patient received 6 cycles of Cystemustine $90 \mathrm{mg} / \mathrm{m}^{2}$. Target size decreased after 2 cycles, and the patient was CR at the end of treatment. No relevant toxicity was reported, except an episode of febrile aplasia after the $6^{\text {th }}$ cycle leading to red blood cells and platelets transfusion.

Patient 5 was a 43 year male presenting with a Clark level III cutaneous thoracic melanoma lesion excised on August 1993. Surgery was completed by a wide local excision margin of $3 \mathrm{~cm}$ of the scar. Disease assessment imaging revealed no metastasis. The patient was then followed every 3 months.
Several pulmonary node metastasis were found in March 1998. The patient received 8 cycles of dacarbazine, and because of new disease progression, he received six cycles of Cystemustine $60 \mathrm{mg} / \mathrm{m}^{2}$ every 2 weeks. The patient was considered in complete remission after 2 cycles of Cystemustine. No significant toxicity was reported during the treatment.

Among these five patients, three remain in long-term remission for 14, 7 and 6 years after Cystemustine monotherapy. Of the other 2 patients, one (patient 1) died from a stroke after a 12 years survival without disease recurrence. The second (patient 3 ) presented with a myelodysplastic syndrome treated with cytarabine. This patient died in March 2000 from severe aplasia, and at this time her melanoma was still in complete remission after 9 years.

\section{Conclusion}

Although some reports had already described long-term survival in patients with metastatic melanoma treated with chemotherapy, most of these results were observed for patients treated with chemotherapy in association, or with chemotherapy alone followed by surgery. In a phase III study, 580 patients were treated with dacarbazine (Deticene $\left.^{\circledast}\right)$ alone or in association with carmustine, lomustine, vincristine or an hydroxyurea. Hill et al. [2] reported 8 patients, with complete response who survived 6 years after the treatment. Ahmann et al. [9] gave results for 15 clinical studies. Among the 503 patients, 6 presented with complete response and long term survival of seven years or longer. Four patients have been treated with a semustine based regimen, one with a combination of vinblastine, bleomycin and cisplatin, and the last one with dianthydrogalacticol.

Petit et al. [5] described 5 out of 160 patients who went into long-term remission 7 years after fotemustine chemotherapy followed by surgery. In Samuel et al. [6], 40 patients with symptomatic metastatic melanoma were treated with procarbazine, vincristine and lomustine (POC). Among them, two remained in complete remission at 6 and 6.5 years. Berd et al. [3] treated 147 patients with a combination of carmustine, dacarbazine and cisplatin. Among the 17 complete response, 7 patients presented with long-term survival (19 to 82 months).

Coates et al. also described the case of 8 patients who remain in long-term remission 4 to 15 years after chemotherapy for visceral metastatic melanoma among some 1100 patients with visceral melanoma who have received chemotherapy, almost always with single agent dacarbazine or a nitrosourea treatments. For these patients, the mechanism remains uncertain, but the author suggested 
that chemotherapeutic agents can cause mutations that allow expression of antigenicity in tumour cells [4].

Despite these noteworthy and encouraging but also rare results, it appears essential to increase cystemustine efficiency. The main antitumor target of CENU is DNA with generation of $\mathrm{O}^{6}$-chloroethylguanine and cross-linking with cDNA strands [10]. The MGMT (O6-methylguanineDNA methyltransferase) protein removes O6-alkylguanine by accepting the alkyl group on the cystein residue of its active site. MGMT level varies considerably in normal and tumor cells, and cells that exhibit a low MGMT level are more sensitive to CENU [11]. Methionine restriction is known to inhibit growth of human and animal tumor (in vitro, and in vivo) [12]. It decreases MGMT mRNA and activity in tumoral cells [13]. Furthermore, the potentiating effect of methionine depletion on Cystemustine treatment has been shown in B16 melanoma-bearing mice [14]. On the basis of these previous experimental results, we have initiated a phase-I clinical trial of dietary methionine restriction, in association with Cystemustine treatment for adults with recurrent metastatic melanomas.

In conclusion, we described case of five out 53 patients with metastatic melanoma, treated with Cystemustine, 60 or $90 \mathrm{mg} / \mathrm{m}^{2}$, and presented with complete response and long-term disease-free survival. Despite these encouraging results, it appears crucial to increase cystemustine efficiency.

\section{Competing interests}

The author(s) declare that they have no competing interests.

\section{Author's contributions}

XD was involved in patient treatment and participated in writing the manuscript.

ET was responsible for data management, and participated in writing the manuscript.

MD'I, AS and PC were involved in patient treatment and participated in drafting the manuscript.

JCM has provided Cystemustine and participated in drafting the manuscript.

All authors read and approved the final manuscript.

\section{References}

I. Bajetta E, Del Vecchio M, Bernard-Marty C, Vitali M, Buzzoni R, Rixe O, Nova P, Aglione S, Taillibert S, Khayat D: Metastatic melanoma: chemotherapy. Semin Oncol 2002, 29:427-445.

2. Hill GJ 2nd, Krementz ET, Hill HZ: Dimethyl triazeno imidazole carboxamide and combination therapy for melanoma. IV. Late results after complete response to chemotherapy
(Central Oncology Group protocols 7 I3I, and 7I3IA). Cancer 7|30, 53:1299-1305.

3. Berd D, Mastrangelo MJ: Combination chemotherapy of metastatic melanoma. J Clin Oncol 1995, I3:796-797.

4. Coates AS, Segelov E: Long term response to chemotherapy in patients with visceral metastatic melanoma. Ann Oncol 1994, 5:249-25I.

5. Petit T, Borel C, Rixe O, Avril MF, Monnier A, Giroux B, Weil M, Khayat $D$ : Complete remission seven years after treatment for metastatic malignant melanoma. Cancer 1996, 77:900-902.

6. Samuel LM, Harvey VJ, Mitchell PL, Thompson PI, Mak D, Melville P, Evans BD: Phase II trial of procarbazine, vincristine and lomustine (POC) chemotherapy in metastatic cutaneous malignant melanoma. Eur J Cancer 1994, 30A:2054-2056.

7. Godeneche D, Madelmont JC, Moreau MF, Duprat J, Plagne R, Meyniel G: Metabolism of 2-chloroethyl nitrosocarbamoylcystamine by rat liver subcellular fractions. Drug Metab Dispos 1986, 14:112-II7.

8. Filippeschi S, Colombo T, Bassani D, De Francesco L, Arioli P, D'Incalci M, Bartosek I, Guaitani A: Antitumor activity of the novel nitrosourea S10036 in rodent tumors. Anticancer Res 1988, 8: I35I-1354.

9. Ahmann DL, Creagan ET, Hahn RG, Edmonson JH, Bisel HF, Schaid DJ: Complete responses and long-term survivals after systemic chemotherapy for patients with advanced malignant melanoma. Cancer 1989, 63:224-227.

10. Demidem A, Morvan D, Papon J, De Latour M, Madelmont JC: Cystemustine induces redifferentiation of primary tumors and confers protection against secondary tumor growth in a melanoma murine model. Cancer Res 200 I, 6 I:2294-2300.

II. Paz MF, Yaya-Tur R, Rojas-Marcos I, Reynes G, Pollan M, AguirreCruz L, Garcia-Lopez JL, Piquer J, Safont MJ, Balana C, Sanchez-Cespedes M, Garcia-Villanueva M, Arribas L, Esteller M: CpG island hypermethylation of the DNA repair enzyme methyltransferase predicts response to temozolomide in primary gliomas. Clin Cancer Res 2004, 10:4933-4938.

12. Cellarier E, Terret C, Labarre P, Ouabdesselam R, Cure H, Marchenay C, Maurizis JC, Madelmont JC, Cholle P, Armand JP: Pharmacokinetic study of cystemustine, administered on a weekly schedule in cancer patients. Ann Oncol 2002, 13:760-769.

13. Kokkinakis DM, von Wronski MA, Vuong TH, Brent TP, Schold SC Jr: Regulation of O6-methylguanine-DNA methyltransferase by methionine in human tumour cells. $\mathrm{Br} J$ Cancer 1997, 75:779-788.

14. Morvan D, Papon J, Madelmont JC, Demidem A: Methionine deprivation potentiates the effect of cystemustine treatment on B 16 melanoma tumors in syngenic recipients. AACR, San Francisco 2002:3822.

\section{Pre-publication history}

The pre-publication history for this paper can be accessed here:

http://www.biomedcentral.com/1471-2407/5/147/pre pub

Publish with Biomed Central and every scientist can read your work free of charge

"BioMed Central will be the most significant development for disseminating the results of biomedical research in our lifetime. "

Sir Paul Nurse, Cancer Research UK

Your research papers will be:

- available free of charge to the entire biomedical community

- peer reviewed and published immediately upon acceptance

- cited in PubMed and archived on PubMed Central

- yours - you keep the copyright 